\title{
FULL WAFER INTEGRATION OF SHAPE MEMORY ALLOY MICROACTUATORS USING ADHESIVE BONDING
}

\author{
N. Sandström*, S. Braun, G. Stemme and W. van der Wijngaart \\ Microsystem Technology Lab, KTH - Royal Institute of Technology, Stockholm, Sweden
}

\begin{abstract}
This paper presents the wafer-scale manufacturing of microactuators based on bulk shape memory alloy material integrated using adhesive bonding. The work addresses key technical challenges related to the wafer-scale fabrication of bulk SMA micro actuators, including wafer-scale integration of patterned SMA sheets to structured Si wafers and the integration of cold state reset layers to the microactuators. Contact printing of an adhesive polymer ensures a selective bonding when transferring full SMA sheets to silicon structures on a patterned wafer. The stressed films deposited on top of the SMA microactuator ensure a built-in reset mechanism of the actuators. The paper reports on the successful wafer-scale integration of wafer-sized SMA sheets and the wafer-scale fabrication of actuator cantilevers. First test cantilevers with a length of $2.5 \mathrm{~mm}$ show a stroke of approx. $180 \mu \mathrm{m}$.
\end{abstract}

\section{KEYWORDS}

Microelectromechanical systems, MEMS, shape memory alloy, SMA, Titanium-Nickel, SMA, microactuator, wafer-scale integration, adhesive bonding

\section{INTRODUCTION}

Structures made of Shape Memory Alloys (SMA) can be easily pseudo-plastically deformed at temperatures below the material-specific transformation temperature $\mathrm{T}_{0}$. This process is reversible, i.e. upon applying heat the structure will recover its original shape. If the recovery is mechanically hindered, the material generates high forces, with the energy density exceeding that of other actuation principles by at least one order of magnitude [1]. After the shape recovery and at temperatures below $\mathrm{T}_{0}$, the structure must again be pseudo-plastically deformed to be operated as an actuator. For most of the SMA actuators, this so-called cold-state reset is provided by an external bias spring. The integration of SMA material in MEMS devices can be summarized in two different approaches. One approach is to fabricate the SMA actuator element and the MEMS structure separately. The bias spring is provided by a mechanical obstruction on the MEMS structure, which deforms the SMA element during the assembly of the SMA element and the MEMS structure [2]. The latter approach features several advantages such as the use of bulk SMA, which is commercially available in a wide thickness range and therefore allows for

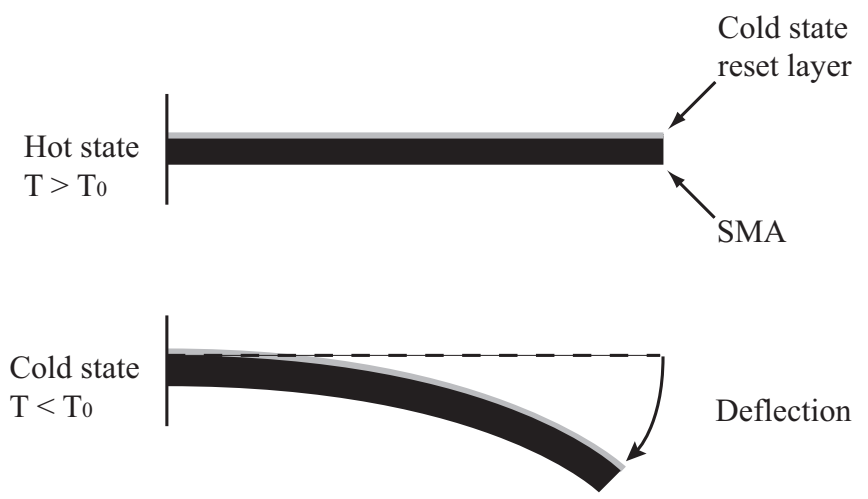

Figure 1: The SMA microactuator is deformed in the cold state due to the induced stress of the deposited cold-state reset layer. Upon heating, the actuator regains its flat shape in the hot state.

adjustable mechanical robustness and reduced material cost. However, the required per-component assembly is not batch compatible and results in unacceptable high costs. Batch processing compatibility is provided by another method, the sputtering of thin SMA films on the MEMS structure [3]. In this approach, the bias spring is provided by the built-in film stress. However, sputtering of SMA is complicated and an annealing of the material at high temperatures is necessary, which implies unwanted interdiffusion processes of the SMA with the substrate. Furthermore, the thicknesses of the films are limited which results in a limited mechanical performance of the actuator. In recent work, pre-strained SMA fibres were integrated to microstructured silicon [4] using silicon cantilevers as cold-state reset.

Previously, the authors introduced a concept for batch manufacturing of robust trimorph bulk SMA microactuators [5], circumventing the limitations of the previous methods. The structure consisted of thin cold-rolled SMA sheet as the bulk material and a dielectric layer which was deposited at an elevated temperature to provide a stressinduced cold state reset. However, there were a number of problems related to this approach. First, thermal mismatch between the SMA and the silicon caused delamination of wafer-sized sheets after adhesive bonding, hence the integrated SMA pieces were limited to postal stamp size. Second, the SMA sheet was patterned after the bonding using an aggressive $\mathrm{HNO}_{3} / \mathrm{HF}$ mixture, which heavily attacked 
the mask material as well as both the underlying adhesive layer and the silicon. The current work presents a method to integrate full wafer-sized SMA sheets to microstructured silicon wafers. To avoid the thermal stress related issues as well as the aggressive SMA etchant attacking the adhesive and silicon structure, the SMA sheet is patterned prior to the adhesive bonding.

\section{WAFER-SCALE MANUFACTURING OF SMA MICROACTUATORS}

\section{Cold-state reset of bulk SMA microactuators}

The proposed actuator contains two functional layers as shown in Figure 1). One functional layer is the core actuation layer formed by the SMA bulk material, which provides benefits such as the commercial availability of material thicknesses and precise control of alloy composition defining the SMA material characteristics [1]. The other functional layer is a stressed film which deforms the actuator in the cold state and, in contrast to previous bulk SMA micro actuators, eliminates the pick-and-place integration of an additional spring element. Besides the batch compatibility of depositing stressed thin films, this method also allows for tuning the actuator characteristics by the choice of layer thicknesses, material deposition technology and conditions.

In the current work, three different materials were tested as cold-state reset layer. The tested materials are intrinsically stressed, PECVD deposited $\mathrm{SiO}_{2}$ and $\mathrm{Si}_{3} \mathrm{~N}_{4}$ films as well as aluminium, which was sputter-deposited at elevated temperatures and results in a standard thermal bimorph structure. The layers were deposited on $30 \mu \mathrm{m}$ thick SMA sheets (Johnson-Matthey, USA). The SMA sheets were then diced into cantilevers with a width and length of $2 \mathrm{~mm}$ and $10 \mathrm{~mm}$, respectively.

The average curvatures, $\kappa=1 / \mathrm{R}$, with $\mathrm{R}$ being the radius of curvature, are presented in Table 1 for each material. The $\mathrm{Si}_{3} \mathrm{~N}_{4}$ and $\mathrm{Al}$ films deflected the SMA cantilevers in the cold state but upon heating the bulk SMA was able to regain a close-to-flat shape. The $\mathrm{SiO}_{2}$ film was able to strongly deflect the SMA bulk in the cold state but due to the large stress from the dielectric film the bulk SMA was not able to recover its flat shape upon heating. However, with a proper selection of film thicknesses and deposition parameters both the dielectric materials and the metal film are considered to be useful as cold state reset material layers for SMA microactuators

\section{Wafer-scale integration of bulk SMA material}

To avoid the thermal stress related issues as well as the aggressive SMA etchant attacking the adhesive and silicon structure, the SMA sheet was patterned prior to the adhesive bonding. To keep the mechanical integrity of the SMA sheet, the single actuator structures are interconnected with thin
Table 1: Curvature of $30 \mu \mathrm{m}$ thick SMA cantilevers with different cold state reset layers.

\begin{tabular}{cccc}
\hline \multicolumn{2}{c}{ Cold state reset layer } & \multicolumn{2}{c}{ Average curvature, $\kappa=1 / \mathrm{R}$} \\
Material & Thickness & $\mathrm{T}<\mathrm{T}_{0}$ & $\mathrm{~T}>\mathrm{T}_{0}$ \\
\hline $\mathrm{SiO}_{2}{ }^{(a)}$ & $1 \mu \mathrm{m}$ & $0.074 \mathrm{~mm}^{-1}$ & $0.014 \mathrm{~mm}^{-1}$ \\
$\mathrm{Si}_{3} \mathrm{~N}_{4}(a)$ & $1 \mu \mathrm{m}$ & $0.021 \mathrm{~mm}^{-1}$ & flat \\
$\mathrm{Al}^{(b)}$ & $1 \mu \mathrm{m}$ & $0.045 \mathrm{~mm}^{-1}$ & flat \\
\hline
\end{tabular}

(a) PECVD at $300{ }^{\circ} \mathrm{C}$; ${ }^{(b)}$ sputtered at $120^{\circ} \mathrm{C}$

SMA lines. To allow for the handling and etching of the thin SMA sheet, the sheet was temporarily bonded to a carrier substrate.

The SMA etchant used is a acid-nitric acid-acetic acid (HNA) etch system [6], which isotropically etches silicon, but also attacks many metals and some photoresists [7]. This complicates the choice of a compatible masking material to achieve an acceptable selectivity. In the current work, five different materials were tested as masking materials for the SMA etching. The tested materials were a positive and a negative photoresist $(1.2 \mu \mathrm{m}$ and $2.8 \mu \mathrm{m}$, respectively), plasma enhanced chemical vapor deposited (PECVD), $200 \mathrm{~nm}$ thick $\mathrm{SiO}_{2}$ and $\mathrm{Si}_{3} \mathrm{~N}_{4}$ layers as well as $200 \mathrm{~nm}$ thick sputtered Au. Both photoresists were found to be unusable as a masking material. The $\mathrm{SiO}_{2}$ and $\mathrm{Si}_{3} \mathrm{~N}_{4}$ films were etched with an unacceptably low selectivity towards the SMA. The Au was not etched at all and therefore identified as the best masking material, which agrees with previous work [6].

The patterned SMA sheet was bonded on the silicon wafer using adhesive bonding [8]. The adhesive layer must not cover the SMA microactuator beam to avoid any unwanted stress deformation of the SMA. Therefore, instead of applying the adhesive on the SMA sheet, the adhesive was applied on the silicon structures using an adapted transfer contact printing process [9]. The BCB was spun onto the adhesive side of standard $65 \mu \mathrm{m}$ thick dicing blue tape SWT $10+$ (Nitto-Denko) and then stamped on the top surface of the microstructured wafer.

\section{Fabrication of test structures}

Figure 2 illustrates the fabrication of the first test structures. A $30 \mu \mathrm{m}$ thick SMA sheet (Johnson-Matthey, USA) was first flattened by heating it above $\mathrm{T}_{0}=45^{\circ} \mathrm{C}$, and subsequentially a 50/200 nm thick TiW/Au layer was sputtered to serve as a hard mask for the etching of the SMA sheet. Then, the SMA sheet was temporarily adhesively bonded to a Si handle wafer. The TiW/Au layer was patterned by standard positive photolithography and wet chemical etching after which the SMA sheet was etched to form cantilevers with 


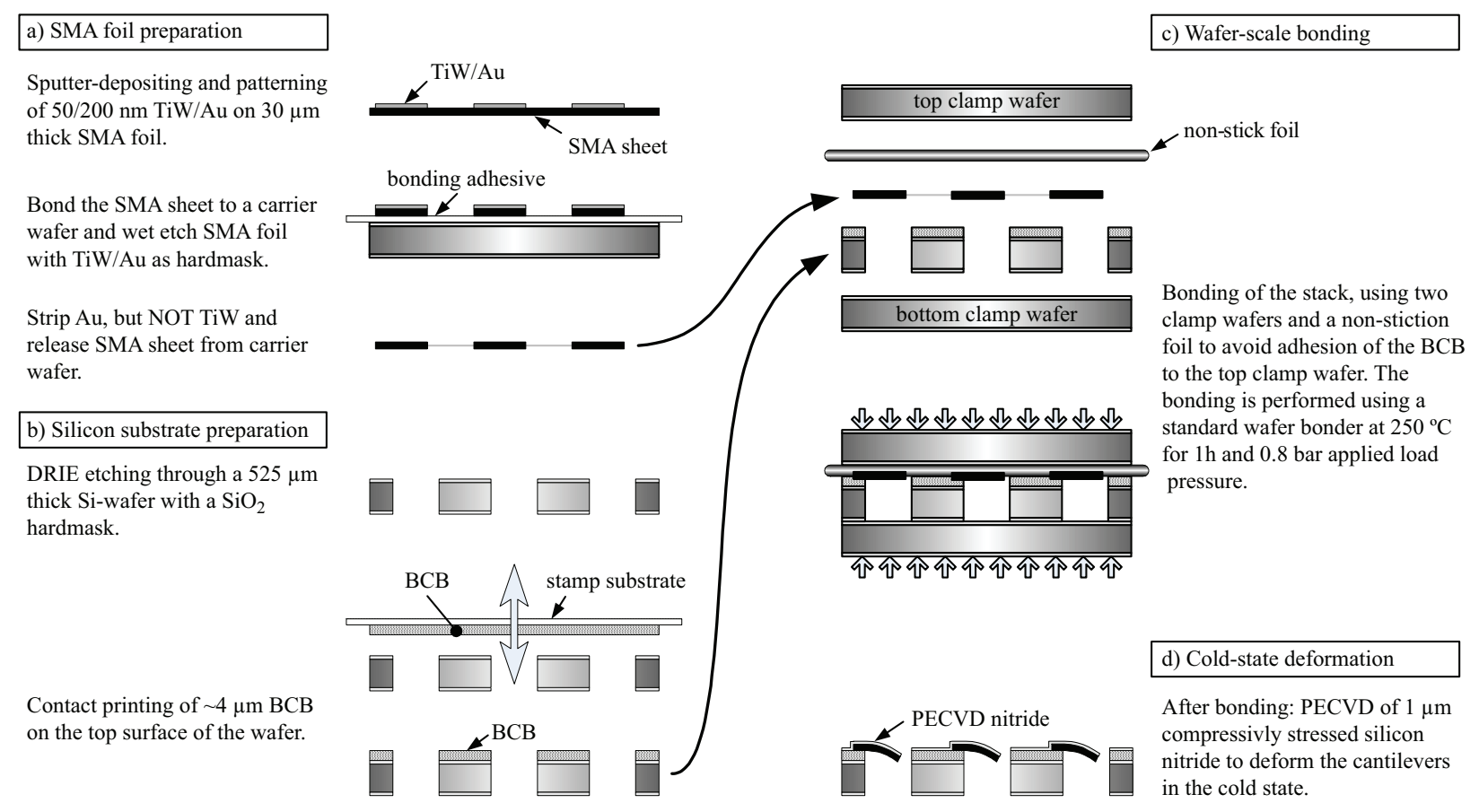

Figure 2: Fabrication scheme for the test structures.

a width and length of $1 \mathrm{~mm}$ and $2.5 \mathrm{~mm}$, respectively. Then, the Au layer was stripped off by wet chemical etching but the TiW layer was left as an adhesion promoter for the BCB. Finally, the stack was put in a bath of Acetone to release the SMA sheet as well as to strip off the resist.

A $525 \mu \mathrm{m}$ thick Si wafer was prepared by thermally oxidizing a $2 \mu \mathrm{m}$ thick oxide layer which was patterned by standard positive photolithography followed by wet chemical etching in buffered hydrofluoric acid (BHF). With the oxide layer as an etch mask, through holes were etched by using deep reactive ion etching (DRIE). Thereafter, BCB Cyclotene 3022-46 (DOW, USA) was stamped onto the nonetched areas of the $\mathrm{Si}$ wafer using the stamping technique described previously. To integrate the patterned SMA sheet with the structured $\mathrm{Si}$ wafer, the sheet was aligned to the structures of the wafer and placed on the adhesive layer. During the hardcuring of the $\mathrm{BCB}$, the stack was placed it between two clamping wafers with a non-stick sheet between the SMA sheet and the top clamping to avoid unwanted bonding to the clamping wafer. Then, the stack was hard-cured in a wafer bonder during $1 \mathrm{~h}$ at a temperature of $250{ }^{\circ} \mathrm{C}$ and an applied load pressure of 0.8 bar. After the bonding, the cold state reset layer was deposited using plasma enhanced chemical vapor deposition (PECVD). One one stack, $\mathrm{Si}_{3} \mathrm{~N}_{4}$ was deposited on the top side of the SMA, while on another stack, $\mathrm{SiO}_{2}$ was deposited on the backside of the SMA through the holes in the Si.

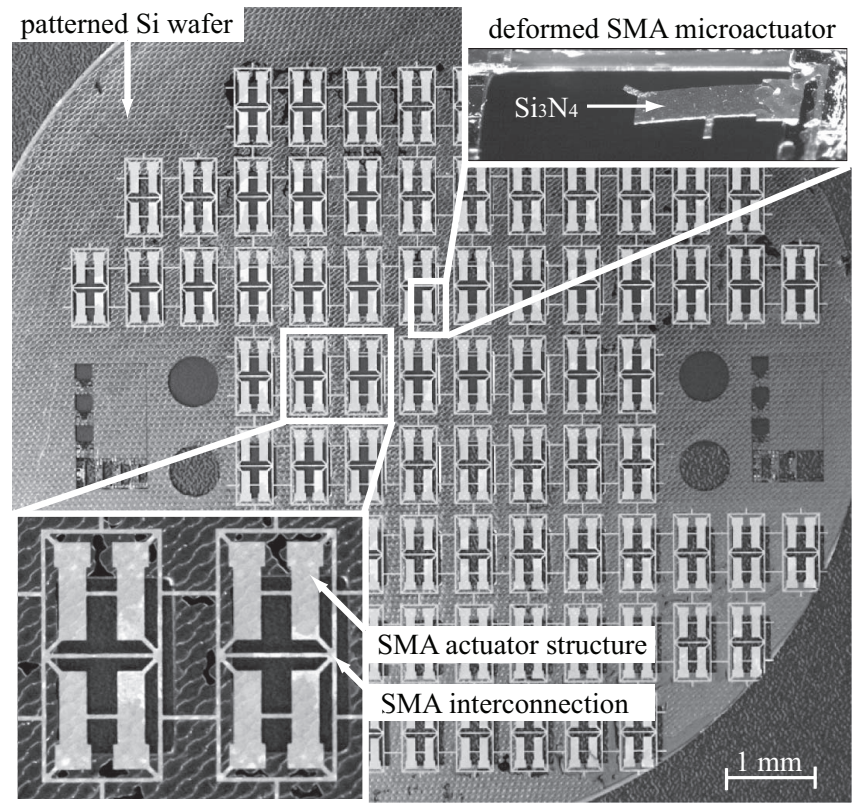

Figure 3: Photograph of wafer-scale patterned and bonded SMA microactuators. The bottom-left inset shows the actuator structures and the interconnecting SMA lines while the top-right inset shows a released actuator cantilever deflected downwards due to the compressive stress of the $1 \mu \mathrm{m}$ $\mathrm{Si}_{3} \mathrm{~N}_{4}$ layer on top. 


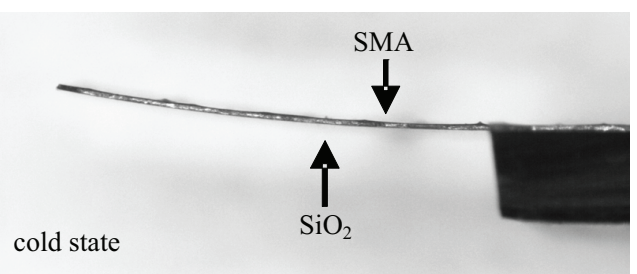

(a)

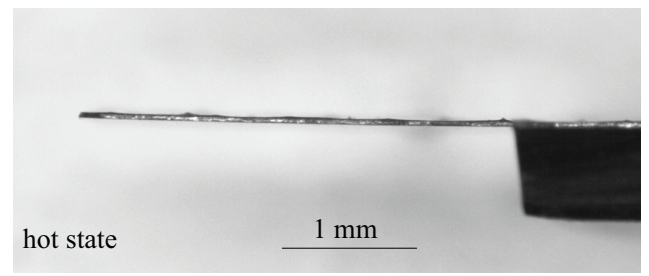

(b)

Figure 4: Photographs of a single SMA microactuator diced out from a full wafer with a $1 \mu \mathrm{m} \mathrm{SiO}{ }_{2}$ cold state reset layer on the bottom side. The cantilever is shown deflected upwards in the cold state (a) and close-to-flat in the hot state (b). The tip stroke was measured to be approximately $180 \mu \mathrm{m}$.

\section{RESULTS}

Integrated SMA microactuators were successfully fabricated and bonded to structured $\mathrm{Si}$ wafers as shown in Figure 3. Structures with a $1 \mu \mathrm{m}$ thick $\mathrm{Si}_{3} \mathrm{~N}_{4}$ cold reset layer deflected downwards whereas structures with a $1 \mu \mathrm{m}$ thick $\mathrm{SiO}_{2}$ cold state reset layer deflected upwards in the cold state, due to the compressive stresses from the dielectric layer. Figure 4 shows SMA cantilevers with a $\mathrm{SiO}_{2}$ cold state reset layer, which are deflected upwards in the cold state (a) and close-to-flat in the hot state (b). The stroke of this cantilever was optically measured in a microscope to approximately $180 \mu \mathrm{m}$.

\section{CONCLUSIONS}

This paper has shown the wafer-scale and batch compatible manufacturing of bulk SMA microactuators. It also demonstrated the wafer-scale integration of SMA microactuators to structured Si wafers and cold state reset layers. The integration concept was successfully realized with the wafer-scale fabrication of cantilever demonstrators based on bulk SMA in combination with $\mathrm{Si}_{3} \mathrm{~N}_{4}$ and $\mathrm{SiO}_{2}$ dielectric cold state reset layers.

\section{ACKNOWLEDGEMENTS}

This work is part of the Q2M project and receives research funding from the European Commission through the 6th Framework Programme.

\section{REFERENCES}

[1] M. Kohl, Shape Memory Microactuators. Springer, 2004.

[2] K. Skrobanek, M. Kohl, and S. Miyazaki, "Stressoptimised shape memory microvalves," in Micro Electro Mechanical Systems, 1997. MEMS '97, Proceedings, IEEE., Tenth Annual International Workshop on, 1997, pp. 256-261.

[3] P. Krulevitch, A. Lee, P. Ramsey, J. Trevino, J. Hamilton, and M. Northrup, "Thin film shape memory alloy microactuators," Journal of Microelectromechanical Systems, vol. 5, no. 4, pp. 270 - 82, December 1996.

[4] D. Clausi, H. Gradin, S. Braun, J. Peirs, G. Stemme, D. Reynaerts, and W. van der Wijngaart, "Microactuation utilizing wafer-level integrated SMA wires," in Proceedings of the IEEE International Conference on Micro Electro Mechanical Systems (MEMS), 2009, pp. $1067-$ 1070.

[5] N. Sandström, S. Braun, G. Stemme, and W. van der Wijngaart, "Wafer-scale manufacturing of robust trimorph bulk SMA microactuators," in Proceedings of the 11 th international conference on new actuators (ACTUATOR), 2008, pp. 382-385.

[6] J. Gill, K. Ho, and G. Carman, "Three-dimensional thin-film shape memory alloy microactuator with twoway effect," Journal of Microelectromechanical Systems, vol. 11, no. 1, pp. 68 - 77, 2002/02/.

[7] K. Williams, K. Gupta, and M. Wasilik, "Etch rates for micromachining processing-Part II," Journal of Microelectromechanical Systems, vol. 12, no. 6, pp. 761 - 78, 2003/12/.

[8] F. Niklaus, G. Stemme, J. Q. Lu, and R. J. Gutmann, "Adhesive wafer bonding," Journal of Applied Physics, vol. 99, no. 3, p. 031101, February 2006.

[9] J. Oberhammer and G. Stemme, "BCB contact printing for patterned adhesive full-wafer bonded 0-level packages," Journal of Microelectromechanical Systems, vol. 14 , no. 2, pp. 419 - 25, 2005/04/.

\section{CONTACT}

* N. Sandström, tel: +46-8-790-9231;

niklas.sandstroem@ee.kth.se 